\section{Closing the hominid gap}

\section{Glenn C. Conroy}

Origins Reconsidered: In Search of What Makes Us Human. By Richard Leakey and Roger Lewin. Doubleday/Little, Brown: 1992. Pp. 375. \$25, £18.99.

In the hands of skilled storytellers, the international race to close the 'hominid fossil gap' has all the excitement, romance and intrigue of a modern-day Manhattan Project - the only difference is that human-origins research is often portrayed as being more explosive. In Differences between these two species...

their comfortably chatty and familiar style, Richard Leakey and Roger Lewin use the recent discoveries of a nearly complete Homo erectus skeleton (the 'Turkana Boy') and a hyper-robust australopithecine cranium (the 'Black Skull') as convenient launching pads for this sequel to their successful previous collaboration, Origins, which was published in 1977. Leakey's unique personal history combined with Lewin's crisp, engaging writing style results in an enjoyable, fast-paced read.

Leakey is described on the dust jacket as "the world's most famous living paleoanthropologist", leaving me to ponder whom the publisher's regard as the world's most famous dead palaeoanthropologist. The only disappointing aspect of the book's production is the poor choice and marginal quality of the photographs. Inexplicably, there is only one (inadequate) photo each of the Turkana Boy and the Black Skull, even though they are the centrepieces of the story.

Both discoveries provide important new insights into human evolution, particularly the Homo erectus skeleton. Most evolutionary hypotheses can be broken down into three analytical levels: the cladogram, the phylogenetic tree and the scenario. Unlike cladograms and phylograms, scenarios are not diagrams but, rather, historical narratives that describe not only phylogenetic relationships but also the ecological and evolutionary forces that most directly influence the organisms under discussion. The scenario, being more hypothetical and interpretive than the cladogram or phylogenetic tree, is the level around which most verbal fisticuffs in palaeoanthropology arise. For the most part, Leakey and Lewin spare the reader any dogmatic pronouncements on the first level of analysis and quickly get to the more interesting, and of course more controversial, second and third levels. As a refreshing antidote to the metastases of cladistic theology in palaeoanthropology, they place more emphasis on how these discoveries affect our notions about human evolutionary grades and the biological adaptations shown by each (for example, australopithecine versus Homo erectus grades of adaptation). This is the most enjoyable, informative and illumi-

publicly". The audience is thus left to its own imagination: let's see -- espionage? ivory smuggling? polyester safari suits? ordering red wine with fish?

While the narrative of the book is a relatively straightforward account of discovery and interpretation, a certain amount of poetic licence creeps into the story. For example, molecular biologists would be surprised to learn, and David Pilbeam would blush to read, that it was Pilbeam's "shift in position" that legitimized the field of molecular anthropology. Similarly, Phillip Tobias might shake his head to read that Raymond Dart "unearthed many hominid fossils between the $1930 \mathrm{~s}$ and 1950 s from four main cave sites in South Africa". As far as I am aware, until the fossils discovered at Makapansgat in the late 1940 s by Tobias and colleagues rekindled his interest in palaeoanthropology, Dart displayed little personal initiative in exploring the cave sites of South Africa (including Taung). Luckily, Robert Broom was not so deterred. In fact, one might draw the analogy that Robert Broom was to Dart what Thomas Huxley was to Darwin.

A number of current debates are reviewed, including the molecular evidence for a human-chimpanzee clade and the 'mitochondrial Eve' story. If it is true, as some molecular anthropologists argue, that two such morphologically palaeoanthropologists fining direct fossil lineages (although Leakey's understandably Kenyacentric view of human evolution does peek through at times). When one considers that all known fossil hominoids from Africa come from only a tiny fraction of the present-day land surface of that continent, it stretches credibility to believe that any direct ancestors of later humans have yet been found. The recent discovery of a Miocene hominoid from northern Namibia is a powerful reminder of how little we know about the geographic distribution of human ancestors.

To be sure, Origins Reconsidered has many of the elements the public now comes to expect from trade books on human origins. There are the usual tales of adventure in remote and dusty places and the heavy dose of male bonding (or 'male bondage' as Dan Quayle once inadvertently called it). Palaeoanthropologists have elevated the 'don't get mad, get even' school of scientific journalism to an art form and the reader does not have to wait long before Leakey and colleague Alan Walker return the favour by effectively 'slam-dunking' Donald Johanson. Leakey teases his audience a bit by lamenting that his personal and professional relationship with Johanson began to deteriorate for unspecified reasons he considers "best not discussed
Australopithecus robustus

Australopithecus africanus
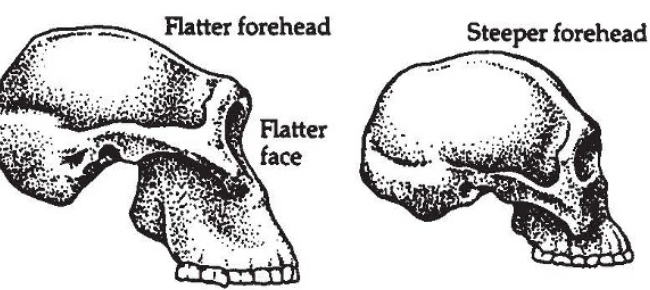

...lie mainly in dental and cranial features.

dissimilar animals as humans and chimpanzees share a more recent common ancestor than two such morphologically similar animals as chimpanzees and gorillas, then palaeontologists have little choice but to pack up their shovels, throw in the towel, and never again attempt another cladogram based on morphological characters. But do molecular anthropologists overstate their case? Vince Sarich once tweaked the collective noses of palaeoanthropologists by writing that "one no longer has the option of considering a fossil specimen older than about eight million years a However, let us remember that the human genome contains some three billion base pairs, so that even 'good' DNA sequence data of 10 kilobase pairs cover only a small fraction of the genome. Given the recent 'mitochondrial Eve' hominid no matter what it looks like". 
fiasco in which flaws in statistical procedures and maximum parsimony analysis of the mitochondrial DNA data using the PAUP computer program have been noted and the conflicting molecular evidence about whether the chimpanzeegorilla-human trichotomy is really resolved, or even resolvable, one 'genioglossus in vestibule' rejoinder to Sarich might be that "one no longer has the option of considering chimpanzees more closely related to humans than to gorillas no matter how good the molecular evidence superficially appears to be"!

To his credit, Leakey is not hung up on giving fossils specific names and seems to understand, unlike many of his peers, that just because one gives a specific name to a fossil does not necessarily mean that one has described a real biological species. The biological species concept is only operative in organisms where reproductive behaviour can be examined in nature (or the laboratory). Species-specific morphological distinctions can only be codified after species are so identified. The process does not work the other way round. One cannot first observe differences in fossils and then claim that these differences define true biological species because, as is well known, morphological differentiation and speciation are not necessarily correlated. One reason evolutionary scenarios are so contentious is that palaeoanthropologists continually name fossil species and then create scenarios based on the artificial constructs they have just created. So, for example, the discovery of the Black Skull may indeed force people to "change their minds", as Leakey and Lewin put it, about australopithecine phylogeny, but only those who bought into the 'orthogenetic' view of australopithecines as evolving linearly from $A$. africanus through $A$. robustus to A. boise i in the first place. For those of us who noted a decade ago that this scheme was unlikely, our views are now reinforced, not changed.

As a self-made man, Leakey has had to put up with a lot from his detractors, some of whom would undoubtedly concur with Disraeli that self-made men often tend to worship their creator. But I, for one, have a great deal of admiration for the man. Part of the reason is that, like me, he studies fossils the old-fashioned way - he tries to find them. But it is his passion for the African bush and the preservation of its vanishing wildlife that resonates most strongly with me. In this, the latest and most difficult challenge of his life, we all must see to it that he succeeds.

Glenn C. Conroy is in the Departments of Anatomy and Neurobiology, and of Anthropology, Washington University Medical School, St Louis, Missouri 63110, USA.

\section{Common-sense consciousness}

\section{Stuart Sutherland}

The Rediscovery of the Mind. By John R. Searle. MIT Press: 1992. Pp. 270. $\$ 22.50, £ 19.95$ (hbk); £9.95 (pbk). (Pbk not yet available in the US.)

JUST as the mini-skirt comes and goes in women's clothing, so does consciousness fluctuate in fashion for philosophers. In the past few years, bookshops have been graced or despoiled by shelf-loads of tomes devoted to the subject. Almost all have been turgid and obscurantist. Now, with The Rediscovery of the Mind we have a clear, well written and cogently argued account, which is marked by that unfashionable quality, common sense. In standing up for the existence of consciousness as a fact, John Searle attacks with pleasing acerbity the loonier beliefs of those who have attempted to deny it. For example, of the Churchlands, who claim that mental terms have been invented by ordinary people to explain behaviour ("folk psychology") and therefore have no validity, he asserts: "It is hard to come right out and say that no one ... ever drank because she was thirsty ... but it's easy to challenge something if you can label it in advance as "folk psychology'." And on other efforts to eliminate consciousness by regarding it as identical with a high-level account of certain brain operations, he writes, "If you are tempted to functionalism, I believe you do not need refutation, you need help".

Searle's own view is that "mental phenomena are caused by neurophysiological processes in the brain and are themselves features of the brain" and he rightly insists on the distinction between consciousness and behaviour or even, as Gilbert Ryle put it, dispositions to behave, for "a system could have consciousness without behaviour and behaviour without consciousness." All this is robust common sense and, I believe, unarguable.

Searle runs into trouble, however, when he attempts to specify the relation between consciousness and the brain. He writes, "Consciousness is a higher-level or emergent property of the brain in the utterly harmless sense of 'higher-level' or 'emergent' in which solidity is a higherlevel emergent property of $\mathrm{H}_{2} \mathrm{O}$ molecules when they are in a lattice structure (ice)", but he goes on to deny the reducibility of consciousness to brain function. But if solidity can be reduced to the behaviour of molecules, why cannot consciousness similarly be reduced to the behaviour of the brain of which it is an emergent property? Searle's answer is tortuous. He claims that solidity originally meant the feeling produced by a solid object: the reduction applies not to this feeling but to the property of the object that gives rise to the feeling. This argument does not work: if the solidity of an object can be reduced to the behaviour of its molecules and if the relation between consciousness and the brain is analogous to that between the solidity of an object and the state of its molecules, then surely consciousness should be reducible to brain states. The contention that consciousness is merely an emergent property of brain states cannot therefore be sustained. It is no use Searle arguing, as he does, that such phenomena as magnetism were irreducible before Maxwell and similarly that one day we will have a theory that shows how consciousness emerges from the brain. There must be, and indeed is, something special about consciousness if it is not reducible.

Searle is also weak on the evolution and function of consciousness. He thinks it allows us to make finer discriminations and has no hesitation in assigning to it a causal role in behaviour. But elsewhere he talks of two robots that behave identically, one of which is conscious (because

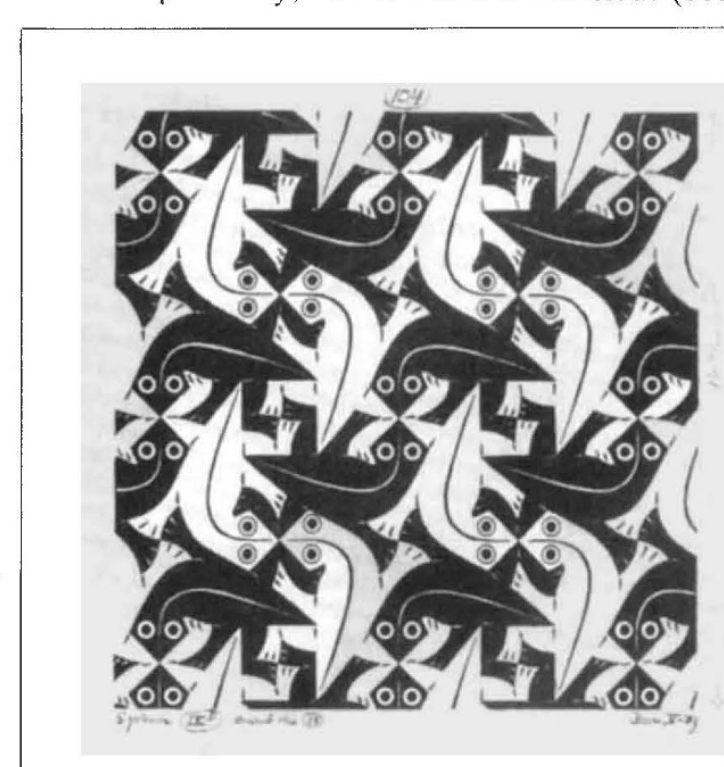

Lizard (1959) by M. C. Escher, one of more than four hundred illustrations reproduced in Doris Schattschneider's beautiful $M$. C. Escher: Visions of Symmetry. The book is now published in paperback by W. H. Freeman, $\mathbf{1 1 9 . 9 5 , ~} \$ 24.95$. For a review, see Nature 349, 471 (1991). 